\title{
A note on some coupled fixed-point theorems on $G$-metric spaces
}

\author{
Hui-Sheng Ding ${ }^{1 *}$ and Erdal Karapınar ${ }^{2}$
}

"Correspondence:

dinghs@mail.ustc.edu.cn

${ }^{1}$ College of Mathematics and Information Science, Jiangxi Normal

University, Nanchang, Jiangxi 330022, People's Republic of China

Full list of author information is available at the end of the article

\begin{abstract}
The purpose of this paper is to extend some recent coupled fixed-point theorems in the context of $G$-metric space by essentially different and more natural way. We state some examples to illustrate our results.
\end{abstract}

MSC: 46N40; 47H10; 54H25; 46T99

Keywords: coupled fixed point; coincidence point; mixed g-monotone property; ordered set; G-metric space

\section{Introduction}

In nonlinear functional analysis, one of the most productive tools is the fixed-point theory, which has numerous applications in many quantitative disciplines such as biology, chemistry, computer science, and additionally in many branches of engineering. In this theory, the Banach contraction principle can be considered as a cornerstone pioneering result which in elementary terms states that each contraction has a unique fixed point in a complete metric space. Due to its potential of applications in the fields above mentioned and many more, the fixed-point theory, in particular, the Banach contraction principle, attracts considerable attention from many authors (see, e.g., [4-30]). Especially, it is considered very natural and curious to investigate the existence and uniqueness of a fixed point for several contraction type mappings in various abstract spaces. A major example in this direction is the work of Mustafa and Sims [19] in which they introduced the concept of G-metric spaces as a generalization of (usual) metric spaces in 2004. After this remarkable paper, a number of papers have appeared on this topic in the literature (see, e.g., $[1-8,10,12,18-29])$.

For the sake of completeness, we recall some basic definitions and elementary results from the literature. Throughout this paper, $\mathbb{N}$ is the set of nonnegative integers, and $\mathbb{N}^{*}$ is the set of positive integers.

Definition 1 (See [19]) Let $X$ be a nonempty set, $G: X \times X \times X \rightarrow \mathbb{R}^{+}$be a function satisfying the following properties:

(G1) $G(x, y, z)=0$ if $x=y=z$,

(G2) $0<G(x, x, y)$ for all $x, y \in X$ with $x \neq y$,

(G3) $G(x, x, y) \leq G(x, y, z)$ for all $x, y, z \in X$ with $y \neq z$,

(G4) $G(x, y, z)=G(x, z, y)=G(y, z, x)=\cdots$ (symmetry in all three variables),

(G5) $G(x, y, z) \leq G(x, a, a)+G(a, y, z)$ for all $x, y, z, a \in X$ (rectangle inequality). 
Then the function $G$ is called a generalized metric, or more specially, a $G$-metric on $X$, and the pair $(X, G)$ is called a $G$-metric space.

Every $G$-metric on $X$ defines a metric $d_{G}$ on $X$ by

$$
d_{G}(x, y)=G(x, y, y)+G(y, x, x), \quad \text { for all } x, y \in X .
$$

Example 2 Let $(X, d)$ be a metric space. The function $G: X \times X \times X \rightarrow[0,+\infty)$, defined by

$$
G(x, y, z)=\max \{d(x, y), d(y, z), d(z, x)\}
$$

or

$$
G(x, y, z)=d(x, y)+d(y, z)+d(z, x)
$$

for all $x, y, z \in X$, is a $G$-metric on $X$.

Definition 3 (See [19]) Let $(X, G)$ be a $G$-metric space, and let $\left\{x_{n}\right\}$ be a sequence of points of $X$, therefore, we say that $\left(x_{n}\right)$ is $G$-convergent to $x \in X$ if $\lim _{n, m \rightarrow+\infty} G\left(x, x_{n}, x_{m}\right)=0$, that is, for any $\varepsilon>0$, there exists $N \in \mathbb{N}$ such that $G\left(x, x_{n}, x_{m}\right)<\varepsilon$, for all $n, m \geq N$. We call $x$ the limit of the sequence and write $x_{n} \rightarrow x$ or $\lim _{n \rightarrow+\infty} x_{n}=x$.

Proposition 4 (See [19]) Let $(X, G)$ be a G-metric space. The following are equivalent:

(1) $\left\{x_{n}\right\}$ is G-convergent to $x$,

(2) $G\left(x_{n}, x_{n}, x\right) \rightarrow 0$ as $n \rightarrow+\infty$,

(3) $G\left(x_{n}, x, x\right) \rightarrow 0$ as $n \rightarrow+\infty$,

(4) $G\left(x_{n}, x_{m}, x\right) \rightarrow 0$ as $n, m \rightarrow+\infty$.

Definition 5 (See [19]) Let $(X, G)$ be a $G$-metric space. A sequence $\left\{x_{n}\right\}$ is called a $G$ Cauchy sequence if, for any $\varepsilon>0$, there is $N \in \mathbb{N}$ such that $G\left(x_{n}, x_{m}, x_{l}\right)<\varepsilon$ for all $m, n, l \geq$ $N$, that is, $G\left(x_{n}, x_{m}, x_{l}\right) \rightarrow 0$ as $n, m, l \rightarrow+\infty$.

Proposition 6 (See [19]) Let $(X, G)$ be a G-metric space. Then the following are equivalent:

(1) the sequence $\left\{x_{n}\right\}$ is G-Cauchy,

(2) for any $\varepsilon>0$, there exists $N \in \mathbb{N}$ such that $G\left(x_{n}, x_{m}, x_{m}\right)<\varepsilon$, for all $m, n \geq N$.

Definition 7 (See [19]) A G-metric space $(X, G)$ is called G-complete if every G-Cauchy sequence is $G$-convergent in $(X, G)$.

Definition 8 Let $(X, G)$ be a $G$-metric space. A mapping $F: X \times X \times X \rightarrow X$ is said to be continuous if for any three $G$-convergent sequences $\left\{x_{n}\right\},\left\{y_{n}\right\}$ and $\left\{z_{n}\right\}$ converging to $x, y$, and $z$, respectively, $\left\{F\left(x_{n}, y_{n}, z_{n}\right)\right\}$ is $G$-convergent to $F(x, y, z)$.

Definition 9 Let $F: X \times X \rightarrow X$ and $g: X \rightarrow X$ be mappings. The mappings $F$ and $g$ are said to commute if

$$
g(F(x, y))=F(g(x), g(y)), \quad \text { for all } x, y \in X .
$$


In [27], Shatanawi proved the following theorems.

Theorem 10 Let $(X, G)$ be a G-metric space. Let $F: X \times X \rightarrow X$ and $g: X \rightarrow X$ be two mappings such that

$$
G(F(x, y), F(u, v), F(z, w)) \leq k(G(g x, g u, g z)+G(g y, g v, g w)) \quad \text { for all } x, y, u, v, z, w .
$$

Assume that $F$ and $g$ satisfy the following conditions:

(1) $F(X \times X) \subset g(X)$,

(2) $g(X)$ is G-complete,

(3) $g$ is G-continuous and commutes with $F$.

If $k \in\left[0, \frac{1}{2}\right)$, then there is a unique $x \in X$ such that $g x=F(x, x)=x$.

Corollary 11 Let $(X, G)$ be a complete G-metric space. Let $F: X \times X \rightarrow X$ be a mapping such that

$$
G(F(x, y), F(u, v), F(u, v)) \leq k(G(x, u, u)+G(y, v, v)) \quad \text { for all } x, y, u, v \in X .
$$

If $k \in\left[0, \frac{1}{2}\right)$, then there is a unique $x \in X$ such that $F(x, x)=x$.

In this paper, we aim to extend the above coupled fixed-point results.

\section{Main results}

We start with an example to show the weakness of Theorem 10.

Example 12 Let $X=[0,1]$. Define $G: X \times X \times X \rightarrow[0,+\infty)$ by

$$
G(x, y, z)=|x-y|+|x-z|+|y-z|
$$

for all $x, y, z \in X$. Then $(X, G)$ is a $G$-metric space. Define a map $F: X \times X \rightarrow X$ by $F(x, y)=$ $\frac{1}{3} x+\frac{1}{8} y$ and $g: X \rightarrow X$ by $g(x)=\frac{x}{2}$ for all $x, y \in X$. Then, for all $x, y, u, v, z, w \in X$ with $y=v=w$, we have

$$
\begin{aligned}
G(F(x, y), F(u, v), F(z, w)) & =G\left(\frac{1}{3} x+\frac{1}{8} y, \frac{1}{3} u+\frac{1}{8} v, \frac{1}{3} z+\frac{1}{8} w\right) \\
& =\frac{|x-u|+|x-z|+|u-z|}{3}
\end{aligned}
$$

and

$$
\begin{aligned}
G(g x, g u, g z)+G(g y, g v, g w) & =G\left(\frac{x}{2}, \frac{u}{2}, \frac{z}{2}\right)+G\left(\frac{y}{2}, \frac{v}{2}, \frac{w}{2}\right) \\
& =\frac{|x-u|+|x-z|+|u-z|}{2} .
\end{aligned}
$$

Then it is easy to that there is no $k \in\left[0, \frac{1}{2}\right)$ such that

$$
G(F(x, y), F(u, v), F(z, w)) \leq k[G(g x, g u, g z)+G(g y, g v, g w)]
$$


for all $x, y, u, v, z, w \in X$. Thus, Theorem 10 cannot be applied to this example. However, it is easy to see that 0 is the unique point $x \in X$ such that $x=g x=F(x, x)$.

We now state our first result which successively guarantee a coupled fixed point.

Theorem 13 Let $(X, G)$ be a G-metric space. Let $F: X \times X \rightarrow X$ and $g: X \rightarrow X$ be two mappings such that

$$
\begin{aligned}
& G(F(x, y), F(u, v), F(u, v))+G(F(y, x), F(v, u), F(v, u)) \\
& \quad \leq k[G(g x, g u, g u)+G(g y, g v, g v)]
\end{aligned}
$$

for all $x, y, u, v \in X$. Assume that $F$ and $g$ satisfy the following conditions:

(1) $F(X \times X) \subset g(X)$,

(2) $g(X)$ is G-complete,

(3) $g$ is G-continuous and commutes with $F$.

If $k \in[0,1)$, then there is a unique $x \in X$ such that $g x=F(x, x)=x$.

Proof Take $x_{0}, y_{0} \in X$. Noting that $F(X \times X) \subset g(X)$, we can construct two sequences $\left\{x_{n}\right\}$ and $\left\{y_{n}\right\}$ in $X$ such that

$$
g x_{n+1}=F\left(x_{n}, y_{n}\right), \quad g y_{n+1}=F\left(y_{n}, x_{n}\right), \quad n \in \mathbb{N} .
$$

Let

$$
M_{n}=G\left(g x_{n}, g x_{n+1}, g x_{n+1}\right)+G\left(g y_{n}, g y_{n+1}, g y_{n+1}\right), \quad n \in \mathbb{N} .
$$

Then, by using (2.1), for each $n \in \mathbb{N}^{*}$, we have

$$
\begin{aligned}
M_{n} & =G\left(g x_{n}, g x_{n+1}, g x_{n+1}\right)+G\left(g y_{n}, g y_{n+1}, g y_{n+1}\right) \\
& =G\left(F\left(x_{n-1}, y_{n-1}\right), F\left(x_{n}, y_{n}\right), F\left(x_{n}, y_{n}\right)\right)+G\left(F\left(y_{n-1}, x_{n-1}\right), F\left(y_{n}, x_{n}\right), F\left(y_{n}, x_{n}\right)\right) \\
& \leq k\left[G\left(g x_{n-1}, g x_{n}, g x_{n}\right)+G\left(g y_{n-1}, g y_{n}, g y_{n}\right)\right] \\
& =k M_{n-1},
\end{aligned}
$$

which yields that

$$
M_{n} \leq k^{n} M_{0}, \quad n \in \mathbb{N} .
$$

Now, for all $m, n \in \mathbb{N}$ with $m>n$, by using rectangle inequality of $G$-metric and (2.2), we get

$$
\begin{aligned}
& G\left(g x_{n}, g x_{m}, g x_{m}\right)+G\left(g y_{n}, g y_{m}, g y_{m}\right) \\
& \leq \quad G\left(g x_{n}, g x_{n+1}, g x_{n+1}\right)+G\left(g x_{n+1}, g x_{m}, g x_{m}\right) \\
& \quad+G\left(g y_{n}, g y_{n+1}, g y_{n+1}\right)+G\left(g y_{n+1}, g y_{m}, g y_{m}\right) \\
& \leq G\left(g x_{n}, g x_{n+1}, g x_{n+1}\right)+G\left(g x_{n+1}, g x_{n+2}, g x_{n+2}\right)+G\left(g x_{n+2}, g x_{m}, g x_{m}\right)
\end{aligned}
$$




$$
\begin{aligned}
& +G\left(g y_{n}, g x_{n+1}, g y_{n+1}\right)+G\left(g y_{n+1}, g y_{n+2}, g y_{n+2}\right)+G\left(g y_{n+2}, g y_{m}, g y_{m}\right) \\
\vdots & \\
\leq & G\left(g x_{n}, g x_{n+1}, g x_{n+1}\right)+G\left(g x_{n+1}, g x_{n+2}, g x_{n+2}\right)+\cdots+G\left(g x_{m-1}, g x_{m}, g x_{m}\right) \\
& +G\left(g y_{n}, g y_{n+1}, g y_{n+1}\right)+G\left(g y_{n+1}, g y_{n+2}, g y_{n+2}\right)+\cdots+G\left(g y_{m-1}, g y_{m}, g y_{m}\right) \\
\leq & M_{n}+M_{n+1}+\cdots+M_{m-1} \\
\leq & \left(k^{n}+k^{n+1}+\cdots+k^{m-1}\right) M_{0} \\
\leq & \frac{k^{n}}{1-k} M_{0},
\end{aligned}
$$

which yields that

$$
\lim _{n, m \rightarrow+\infty} G\left(g x_{n}, g x_{m}, g x_{m}\right)+G\left(g y_{n}, g y_{m}, g y_{m}\right)=0 .
$$

Then, by Proposition 6, we conclude that the sequences $\left\{g x_{n}\right\}$ and $\left\{g y_{n}\right\}$ are G-Cauchy.

Noting that $g(X)$ is $G$-complete, there exist $x, y \in g(X)$ such that $\left\{g x_{n}\right\}$ and $\left\{g y_{n}\right\}$ are $G$ convergent to $x$ and $y$, respectively, i.e.,

$$
\lim _{n \rightarrow+\infty} G\left(g x_{n}, x, x\right)=0, \quad \lim _{n \rightarrow+\infty} G\left(g y_{n}, y, y\right)=0 .
$$

Also, since $g$ is $G$-continuous, we get

$$
\lim _{n \rightarrow+\infty} G\left(g g x_{n}, g x, g x\right)=0, \quad \lim _{n \rightarrow+\infty} G\left(g g y_{n}, g y, g y\right)=0 .
$$

In addition, by (2.1) and the fact $g$ commutes with $F$, we get

$$
\begin{aligned}
& G\left(g g x_{n+1}, F(x, y), F(x, y)\right)+G\left(g g y_{n+1}, F(y, x), F(y, x)\right) \\
& \quad=G\left(g\left(F\left(x_{n}, y_{n}\right)\right), F(x, y), F(x, y)\right)+G\left(g\left(F\left(y_{n}, x_{n}\right)\right), F(y, x), F(y, x)\right) \\
& \quad=G\left(F\left(g x_{n}, g y_{n}\right), F(x, y), F(x, y)\right)+G\left(F\left(g y_{n}, g x_{n}\right), F(y, x), F(y, x)\right) \\
& \quad \leq k\left[G\left(g g x_{n}, g x, g x\right)+G\left(g g y_{n}, g y, g y\right)\right] .
\end{aligned}
$$

Combining this with (2.3), we get

$$
G\left(g g x_{n+1}, F(x, y), F(x, y)\right)+G\left(g g y_{n+1}, F(y, x), F(y, x)\right) \rightarrow 0, \quad n \rightarrow+\infty .
$$

On the other hand, by the fact that $G$ is continuous on its variables (cf. [19]), we have

$$
\begin{aligned}
& G\left(g g x_{n+1}, F(x, y), F(x, y)\right)+G\left(g g y_{n+1}, F(y, x), F(y, x)\right) \\
& \quad \rightarrow G(g x, F(x, y), F(x, y))+G(g y, F(y, x), F(y, x)), \quad n \rightarrow+\infty .
\end{aligned}
$$

Thus, we conclude that

$$
G(g x, F(x, y), F(x, y))+G(g y, F(y, x), F(y, x))=0,
$$


i.e.,

$$
G(g x, F(x, y), F(x, y))=G(g y, F(y, x), F(y, x))=0,
$$

which yields that

$$
g x=F(x, y), \quad g y=F(y, x) .
$$

Moreover, it follows from

$$
\begin{aligned}
& G(g x, g y, g y)+G(g y, g x, g x) \\
& \quad=G(F(x, y), F(y, x), F(y, x))+G(F(y, x), F(x, y), F(x, y)) \\
& \quad \leq k[G(g x, g y, g y)+G(g y, g x, g x)]
\end{aligned}
$$

that $G(g x, g y, g y)+G(g y, g x, g x)=0$. Thus, $G(g x, g y, g y)=0$, i.e., $g x=g y$.

Next, let us show that $g x=F(x, x)=x$. By using rectangle inequality of $G$-metric and (2.1), we have

$$
\begin{aligned}
& G(x, g x, g x)+G(y, g y, g y) \\
& \leq G\left(x, g x_{n+1}, g x_{n+1}\right)+G\left(g x_{n+1}, g x, g x\right)+G\left(y, g y_{n+1}, g y_{n+1}\right)+G\left(g y_{n+1}, g y, g y\right) \\
& \leq {\left[G\left(x, g x_{n+1}, g x_{n+1}\right)+G\left(y, g y_{n+1}, g y_{n+1}\right)\right] } \\
&+\left[G\left(F\left(x_{n}, y_{n}\right), F(x, y), F(x, y)\right)+G\left(F\left(y_{n}, x_{n}\right), F(y, x), F(y, x)\right)\right] \\
& \leq {\left[G\left(x, g x_{n+1}, g x_{n+1}\right)+G\left(y, g y_{n+1}, g y_{n+1}\right)\right]+k\left[G\left(g x_{n}, g x, g x\right)+G\left(g y_{n}, g y, g y\right)\right] } \\
& \leq {\left[G\left(x, g x_{n+1}, g x_{n+1}\right)+G\left(y, g y_{n+1}, g y_{n+1}\right)\right] } \\
&+k[G(x, g x, g x)+G(y, g y, g y)]+k\left[G\left(g x_{n}, x, x\right)+G\left(g y_{n}, y, y\right)\right],
\end{aligned}
$$

which gives that

$$
\begin{aligned}
& G(x, g x, g x)+G(y, g y, g y) \\
& \quad \leq \frac{G\left(x, g x_{n+1}, g x_{n+1}\right)+G\left(y, g y_{n+1}, g y_{n+1}\right)+k\left[G\left(g x_{n}, x, x\right)+G\left(g y_{n}, y, y\right)\right]}{1-k} .
\end{aligned}
$$

Combing this with the fact that $\left\{g x_{n}\right\}$ and $\left\{g y_{n}\right\}$ are G-convergent to $x$ and $y$, respectively, we conclude that

$$
G(x, g x, g x)+G(y, g y, g y)=0,
$$

which yields that

$$
x=g x, \quad y=g y .
$$

Recalling that $g x=g y$ and $g x=F(x, y)$, we get $x=y$ and $x=g x=F(x, x)$. 
It remains to show the uniqueness. Let $u \in X$ be such that $u=g u=F(u, u)$. Then we have

$$
\begin{aligned}
2 G(u, x, x) & =G(F(u, u), F(x, x), F(x, x))+G(F(u, u), F(x, x), F(x, x)) \\
& \leq k[G(g u, g x, g x)+G(g u, g x, g x)] \\
& \leq 2 k G(u, x, x),
\end{aligned}
$$

which yields that $(2-2 k) G(u, x, x) \leq 0$. Thus, $G(u, x, x)=0$, which means $u=x$. This completes the proof.

Remark 14 It is easy to see that Theorem 10, appearing in [27], is a direct corollary of Theorem 13. On the other hand, Theorem 13 can deal with some cases, which Theorem 10 cannot be applied. For this, let us reconsider Example 12. In fact, for all $x, y, u, v \in X$, we have

$$
\begin{aligned}
G & (F(x, y), F(u, v), F(u, v))+G(F(y, x), F(v, u), F(v, u)) \\
& =G\left(\frac{1}{3} x+\frac{1}{8} y, \frac{1}{3} u+\frac{1}{8} v, \frac{1}{3} u+\frac{1}{8} v\right)+G\left(\frac{1}{3} y+\frac{1}{8} x, \frac{1}{3} v+\frac{1}{8} u, \frac{1}{3} v+\frac{1}{8} u\right) \\
& \leq \frac{11(|x-u|+|y-v|)}{12} \\
& =\frac{11}{12}[G(g x, g u, g u)+G(g y, g v, g v)],
\end{aligned}
$$

i.e., (2.1) holds. Other assumptions of Theorem 13 are easy to verify. So, by Theorem 13, there exists a unique $x \in X$ such that $g x=F(x, x)=x$.

Letting $g=I$, we can get the following result.

Corollary 15 Let $(X, G)$ be a complete $G$-metric space. Let $F: X \times X \rightarrow X$ be a mapping such that

$$
\begin{aligned}
& G(F(x, y), F(u, v), F(u, v))+G(F(y, x), F(v, u), F(v, u)) \\
& \quad \leq k[G(x, u, u)+G(y, v, v)]
\end{aligned}
$$

for all $x, y, u, v \in X$. If $k \in[0,1)$, then there is a unique $x \in X$ such that $F(x, x)=x$.

Example 16 Let $(X, G)$ be the same as in Example 12. Then $(X, G)$ is a $G$-metric space. Also, it is not difficult to verify that $(X, G)$ is G-complete. Define a map $F: X \times X \rightarrow X$ by $F(x, y)=1-\frac{1}{16} x^{2}-\frac{5}{16} y^{2}$ for all $x, y \in X$. Then, for all $x, y, u, v \in X$, we have

$$
\begin{aligned}
& G(F(x, y), F(u, v), F(u, v))+G(F(y, x), F(v, u), F(v, u)) \\
& =G\left(1-\frac{1}{16} x^{2}-\frac{5}{16} y^{2}, 1-\frac{1}{16} u^{2}-\frac{5}{16} v^{2}, 1-\frac{1}{16} u^{2}-\frac{5}{16} v^{2}\right) \\
& \quad+G\left(1-\frac{1}{16} y^{2}-\frac{5}{16} x^{2}, 1-\frac{1}{16} v^{2}-\frac{5}{16} u^{2}, 1-\frac{1}{16} v^{2}-\frac{5}{16} u^{2}\right) \\
& \leq \\
& \quad \frac{1}{8}\left|u^{2}-x^{2}\right|+\frac{5}{8}\left|v^{2}-y^{2}\right|+\frac{1}{8}\left|v^{2}-y^{2}\right|+\frac{5}{8}\left|u^{2}-x^{2}\right|
\end{aligned}
$$




$$
\begin{aligned}
& =\frac{3}{4}\left|u^{2}-x^{2}\right|+\frac{3}{4}\left|v^{2}-y^{2}\right| \\
& \leq \frac{3}{2}|u-x|+\frac{3}{2}|v-y|
\end{aligned}
$$

and

$$
\begin{aligned}
& G(x, u, u)+G(y, v, v) \\
& \quad=2(|x-u|+|y-v|) .
\end{aligned}
$$

Thus, the statement (2.4) of Corollary 15 is satisfied for any $k \in\left[\frac{3}{4}, 1\right)$. Thus, there is a unique $x \in X$ such that $F(x, x)=x$.

Remark 17 Corollary 11 cannot be applied to Example 16 since (1.3) does not hold. In fact, if (1.3) holds for some $k \in\left[0, \frac{1}{2}\right)$, then

$$
\begin{aligned}
\frac{9}{40} & =G\left(\frac{11}{16}, \frac{4}{5}, \frac{4}{5}\right)=G\left(F(0,1), F\left(0, \frac{4}{5}\right), F\left(0, \frac{4}{5}\right)\right) \\
& \leq k\left[G(0,0,0)+G\left(1, \frac{4}{5}, \frac{4}{5}\right)\right] \\
& =\frac{2 k}{5} \leq \frac{1}{5}
\end{aligned}
$$

which is a contradiction.

\section{Competing interests}

The authors declare that they have no competing interests.

\section{Authors' contributions}

All authors contributed equally and significantly in writing this paper. All authors read and approved the final manuscript.

\section{Author details}

${ }^{1}$ College of Mathematics and Information Science, Jiangxi Normal University, Nanchang, Jiangxi 330022, People's Republic of China. ${ }^{2}$ Department of Mathematics, Atilim University, İncek, Ankara 06836, Turkey.

\section{Acknowledgements}

The authors are indebted to the referees for their careful reading of the manuscript and valuable suggestions. Hui-Sheng Ding acknowledges support from the NSF of China (11101192), the Key Project of Chinese Ministry of Education (211090) the NSF of Jiangxi Province (20114BAB211002), the Jiangxi Provincial Education Department (GJJ12173), and the Program for Cultivating Youths of Outstanding Ability in Jiangxi Normal University.

Received: 5 May 2012 Accepted: 19 July 2012 Published: 31 July 2012

\section{References}

1. Abbas, M, Sintunavarat, W, Kumam, P: Coupled fixed point of generalized contractive mappings on partially ordered G-metric spaces. Fixed Point Theory Appl. 2012, 31 (2012)

2. Abbas, M, Khan, AR, Nazir, T: Coupled common fixed point results in two generalized metric spaces. Appl. Math. Comput. 217, 6328-6336 (2011)

3. Aydi, H, Karapınar, E: New Meir-Keeler type tripled fixed point theorems on ordered partial metric spaces. Math. Probl. Eng. 2012, Article ID 409872 (2012)

4. Aydi, H, Postolache, $M$, Shatanawi, W: Coupled fixed point results for $(\psi, \phi)$-weakly contractive mappings in ordered G-metric spaces. Comput. Math. Appl. 63(1), 298-309 (2012)

5. Aydi, H, Karapinar, E, Shatnawi, W: Tripled fixed point results in generalized metric spaces. J. Appl. Math. 2012, Article ID 314279 (2012)

6. Aydi, H, Damjanović, B, Samet, B, Shatanawi, W: Coupled fixed point theorems for nonlinear contractions in partially ordered G-metric spaces. Math. Comput. Model. 54, 2443-2450 (2011) 
7. Aydi, H, Shatanawi, W, Vetro, C: On generalized weakly G-contraction mapping in G-metric spaces. Comput. Math. Appl. 62, 4222-4229 (2011)

8. Aydi, H, Karapinar, E, Shatnawi, W: Tripled coincidence point results for generalized contractions in ordered generalized metric spaces. Fixed Point Theory Appl. 2012, 101 (2012)

9. Banach, S: Sur les opérations dans les ensembles abstraits et leur application aux équations intégrales. Fundam. Math. 3, 133-181 (1922)

10. Cho, YJ, Rhoades, BE, Saadati, R, Samet, B, Shatanawi, W: Nonlinear coupled fixed point theorems in ordered generalized metric spaces with integral type. Fixed Point Theory Appl. 2012, 8 (2012)

11. Ding, H-S, Li, L: Coupled fixed point theorems in partially ordered cone metric spaces. Filomat 25(2), 137-149 (2011). doi:10.2298/FIL1102137D

12. Dhutta, PN, Choudhury, BS: A generalization of contraction principle in metric spaces. Fixed Point Theory Appl. 2008 Article ID 406368 (2008)

13. Gnana-Bhaskar, T, Lakshmikantham, V: Fixed point theorems in partially ordered metric spaces and applications. Nonlinear Anal. 65, 1379-1393 (2006)

14. Ćirić, L, Lakshmikantham, V: Coupled fixed point theorems for nonlinear contractions in partially ordered metric spaces. Nonlinear Anal. 70, 4341-4349 (2009)

15. Karapınar, E, Luong, NV, Thuan, NX, Hai, TT: Coupled coincidence points for mixed monotone operators in partially ordered metric spaces. Arabian Journal of Mathematics 1, 329-339 (2012)

16. Karapınar, E: Coupled fixed point theorems for nonlinear contractions in cone metric spaces. Comput. Math. Appl. 59 3656-3668 (2010)

17. Karapınar, E: Couple fixed point on cone metric spaces. Gazi Univ. J. Sci. 24, 51-58 (2011)

18. Mustafa, Z, Aydi, H, Karapınar, E: On common fixed points in G-metric spaces using (E.A) property. Comput. Math. Appl. (2012). doi:10.1016/j.camwa.2012.03.051

19. Mustafa, Z, Sims, B: A new approach to generalized metric spaces. J. Nonlinear Convex Anal. 7(2), 289-297 (2006)

20. Mustafa, Z, Obiedat, H, Awawdeh, F: Some fixed point theorem for mapping on complete G-metric spaces. Fixed Point Theory Appl. 2008, Article ID 189870 (2008)

21. Mustafa, Z, Khandaqji, M, Shatanawi, W: Fixed point results on complete G-metric spaces. Studia Sci. Math. Hung. 48 304-319 (2011)

22. Mustafa, Z, Sims, B: Fixed point theorems for contractive mappings in complete G-metric spaces. Fixed Point Theory Appl. 2009, Article ID 917175 (2009)

23. Mustafa, Z, Shatanawi, W, Bataineh, M: Existence of fixed point results in G-metric spaces. Int. J. Math. Math. Sci. 2009, Article ID 283028 (2009)

24. Luong, VN, Thuan, NX: Coupled fixed point theorems in partially ordered G-metric spaces. Math. Comput. Model. 55 1601-1609 (2012)

25. Shatanawi, W: Fixed point theory for contractive mappings satisfying $\Phi$-maps in G-metric spaces. Fixed Point Theory Appl. 2010, Article ID 181650 (2010)

26. Shatanawi, W: Some fixed point theorems in ordered G-metric spaces and applications. Abstr. Appl. Anal. 2010, Article ID 126205 (2010)

27. Shatanawi, W: Coupled fixed point theorems in generalized metric spaces. Hacet. J. Math. Stat. 40(3), 441-447 (2011)

28. Shatanawi, W, Abbas, M, Nazir, T: Common coupled coincidence and coupled fixed point results in two generalized metric spaces. Fixed Point Theory Appl. 2011, 80 (2011)

29. Tahat, N, Aydi, H, Karapınar, E, Shatanawi, W: Common fixed points for single-valued and multi-valued maps satisfying a generalized contraction in G-metric spaces. Fixed Point Theory Appl. 2012, 48 (2012)

30. Long, W, Rhoades, BE, Rajović, M: Coupled coincidence points for two mappings in metric spaces and cone metric spaces. Fixed Point Theory Appl. 2012, 66 (2012). doi:10.1186/1687-1812-2012-66

doi:10.1186/1029-242X-2012-170

Cite this article as: Ding and Karapınar: A note on some coupled fixed-point theorems on G-metric spaces. Journal of Inequalities and Applications 2012 2012:170.

\section{Submit your manuscript to a SpringerOpen ${ }^{\ominus}$ journal and benefit from:}

- Convenient online submission

Rigorous peer review

- Immediate publication on acceptance

- Open access: articles freely available online

- High visibility within the field

- Retaining the copyright to your article 